\title{
Evidence-Based Use of Antibiotics in Meat Calves
}

\author{
Michael Hässig1 ${ }^{*}$, Sarina Eugster ${ }^{1}$, Fraser Iain Lewis ${ }^{2}$ \\ ${ }^{1}$ Section for Ambulatory Field Clinic and Herd Health, Department of Farm Animals, University of Zurich, \\ Zurich, Switzerland \\ ${ }^{2}$ Section for Epidemiology, University of Zurich, Zurich, Switzerland \\ Email: ${ }^{*}$ mhaessig@vetclinics.uzh.ch
}

Received 4 March 2015; accepted 20 March 2015; published 23 March 2015

Copyright (C) 2015 by authors and Scientific Research Publishing Inc.

This work is licensed under the Creative Commons Attribution International License (CC BY). http://creativecommons.org/licenses/by/4.0/

\section{(c) (i) Open Access}

\begin{abstract}
Abuse of antibiotics is an increasing commonly feature in the media. Widespread preventive use of antibiotics without diagnostics in meat calf husbandry is a major public health concern. In this study, we compare a "trial and error" method, comprising of a first choice antibiotic, followed by a second and third choice (as recommended by the WHO), with a method which utilizes an antibiotic resistance test to first identify the best antibiotic out of first, second or third choice alternatives using decision tree analysis. Data were collected from farms with a known calf herd problem along with antibiograms from those herds. Samples were analysed for resistance to antibiotics against calf pneumonia on a herd level, rather than for resistance against specific antibiotics. Resistance tests were performed on batch samples composed of at least three diseased animals. A deep nasal swap was taken. In nasal swaps only ++ or +++ growth in all 3 samples were used for diagnosis. Other growth of bacteria was considered as contamination. A comparison of resistance rates across a range of antibiotics between farms with known calf pneumonia and calf diarrhoea issues was performed. The decision tree analysis presented provides strong support in favour of an evidence-based approach to antimicrobial treatment by using an antimicrobial resistance test, providing an advantage of $\mathbf{5 8 \%}$ per meat calf against the "trial and error" method, giving a financial gain of some CHF 320.09 under Swiss economic circumstances.
\end{abstract}

\section{Keywords}

Bovine, Calf, Antibiotic, Resistance Test, Decision Tree Analysis

\section{Introduction}

Abuse of antibiotics in meat calf production is an increasingly common theme in both the scientific literature "Corresponding author. 
and public media. The presence and extent of resistance is also an increasing issue in animal husbandry. Meat calves in Switzerland typically leave their farm of origin around the $10^{\text {th }}$ day post partum only protected by a passive immunity, i.e. by the immunity acquired by the colostrum transfer [1]. This early transfer of calves is the result of a high demand for white or light reddish meat by the consumer, resulting in the slaughtering of meat calves at an age of approximately four months. To get an acceptable margin of price by the daily weight gain, the calves have to enter meat calf farms at such an early age. A considerable number of calves show a transfer failure of maternal IgG by colostrum and are not protected at all [2]. Moreover, the protection by colostral antibodies is only present for those infectious agents present in the farm of origin, and not in the new stable where the young beef calves are sent, often in groups of 50 and more, each originating from a potentially different dairy farm. These factors are classical risk factors for diseases related to crowding. To overcome this problem antibiotics are widely used in beef calves. In Switzerland, close to $100 \%$ of calves are treated with antibiotics. Antibiotic treatment is typically used as protective treatment by mixing antibiotics into the milk served by an automatic feeding system, or as an additive in bucket milk. The veterinary practitioner chooses the antibiotic by information on availability by law, commercial availability and information on resistance in time and location. Testing for the presence of antibiotic resistance is not normally performed.

The goal of this study is to proof that correct use of antibiotics by means of an antibiotic resistance test in herd treatment as soon as possible or available after initial treatment by best guess is not only "good veterinary practice" but also economic for the farmer.

We present here, by means of a decision tree analysis, a comparison between the typical "trial and error" approach encompassed by choosing a first choice antibiotic, followed by a second and third choice antibiotic (as recommended by the WHO), with a method which instead utilizes an antibiotic resistance test to first identify the best antibiotic out of first, second or third choice alternatives.

\section{Animal, Material and Methods}

The study data comprised of questionnaire responses and corresponding microbiological test results from cases concerning herd health problems solved in beef calf farms collected by the section for ambulatory clinic and herd health, department for farm animals, university of Zurich between June 1986 and December 2011 [3]. The performance of the herd, the situation of the farm, the herd problems were investigated by a questionnaire $<$ http://www.tierspital.uzh.ch/Nutztiere/Ambulanz/Kontakt.html>. Out of 1847 farms, 49 (2.7\%) had problems with calves and a resistance test was performed.

In 26 cases (34.2\%) the calves were less than or equal to one month of age. All calves were less than 6 months of age.

Samples were analysed for resistance to antibiotics against calf pneumonia on a herd level, rather than for resistance against specific antibiotics. Resistance tests were performed on batch samples composed of at least three diseased animals. A deep nasal swap was taken. In nasal swaps only ++ or +++ growth in all 3 samples were used for diagnosis. Other growth of bacteria was considered as contamination. Bacterial growth is semiquantitatively qualified by the below mentioned microbiological laboratory on a Petri disk. $10 \mu \mathrm{l}$ of the sample are dispersed on the Petri disc. Classification was as following: $-0 \mathrm{CFU},+-<5 \mathrm{CFU}$ (colony forming units), + 5 - 30 CFU, ++ 31 - 100 CFU, +++ $101-500$ CFU and ++++ >501 CFU. All tests were performed either at the institute for Food Security or at the institute for Veterinary Bacteriology of the University of Zurich, according to accredited procedures. A total of 76 bacteriological resistance tests (at farm level) out of 49 farms were evaluated by the above mentioned laboratory staff. The tests used are described in the vademecum of the respective laboratory: <http://www.ivb.uzh.ch/services/DienstleistungenVetBakt/2014_ivb_vademecum.pdf>

(Institute for Veterinary Bacteriology) and

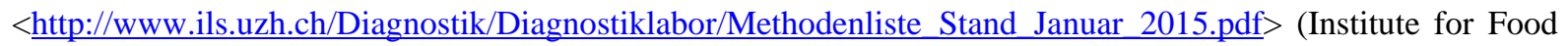
Security).

A decision tree analysis was performed according to Altman [4]. A decision tree is a flowchart in which each node represents an outcome on a decision. Each branch represents the outcome of the test and each leaf node represents a class. The risk of a decision branch is defined as its probability multiplied by it costs. Single risks can be added for the total risk on a certain major branch, also called back calculation. The probabilities of antibiotic resistance are taken out of Hässig et al. [3]. The costs for antibiotics and treatment are taken from the price list in 2012 of the Ambulatory Field Clinic of the Farm Animal Department of the Vetsuisse, Faculty of 
the University of Zurich. The monetary unit is Swiss Francs (CHF). Husbandry and loss of a calf costs were taken from the calculation lists of the Swiss Federal Office for Agriculture. The duration of treatment was assumed to be 10 days. The study unit is one meat calf. The figures are given in Table 1.

\section{Results}

The decision tree is given in Figure 1. The upper main branch is the branch with the standard antibiotic resistance test. A standard antibiotic is only used immediately until the result of the antibiotic resistance test is available. After the test result is available the cheapest antibiotic is chosen with the restriction using first before second and third choice (Figure 1, C1). The lower branch uses no laboratory help, i.e. no antibiotic resistance test, and its decision is made upon the probability of antimicrobial resistance known a priori for the region [3] and WHO guidelines to use first choice antibiotics primarily followed by second and third choice. The costs, i.e. the notations, calculations and probabilities are given in Table 1. The costs are calculated for each decision and cumulated along each main branch. The upper branch in Figure 1, i.e. with the antibiotic resistance test gives total costs of CHF 232.38. The cost for the "trial and error" method in the lower branch gives cost of CHF 552.47. The financial benefit under Swiss economic conditions counts for 58\%.

\section{Discussion}

The decision tree analysis presented was possible due to the availability of previous results in relation to how antimicrobial resistance testing can be translated into clinical decision-making [3]. When dealing with a pneumonic calf the bovine practitioner does not know the aetiology. He or she has to treat according to the symptoms. The probability of a useful antibiotic treatment depends on resistance pattern, temporality and spatiality. Immediate treatment has to be given even as long as the laboratory result is not available [5] [6]. To get an antibiotic resistance test result takes approximately three days. After this time, an etiological or evidence-based therapy is possible. The etiological therapy gives the opportunity not only to use the cheapest antibiotic drug, but also the less important antibiotic drug by means of first, second or third choice or even "reserve antibiotics". As we have shown, using an antibiotic resistance test as the standard operational procedure (SOP), is both ecologically beneficial and economical attractive; costs are reduced by some 58\%. The cost for microbiological testing in Switzerland was set at CHF 30- and the antibiotic resistance test at CHF 50-. This CHF 80- may seem very expensive, but in comparison the Swiss farmer earns about $150 \%$ more for beef calf meat on the Swiss market compared to the European market. Not calculated in this decision is the reduction of test costs in herds because the test has not to be repeated for each calf separately. On the other hand the probabilities given by Hassig et al. [3], especially for good outcomes, are overestimated because other risks or problems at the herd level are not accounted for.

Out of all beef calf farms $44.9 \%$ had problems with pneumonia. Ceftiofur, Florfenicol and Marbofloxacine showed no resistance to meat calf pneumonia in Switzerland. Apramycin was below $10 \%$. Amikacine, Cefquinom, Enrofloxacine and Gentamicine were below 20\%. Over 80\% were Clindamycin, Erythromycin, Lincomycine and Sulfamethoxazole. Tylosine was over 90\%. Metronidazole and Spiramycine showed resistance in 100\% [3].

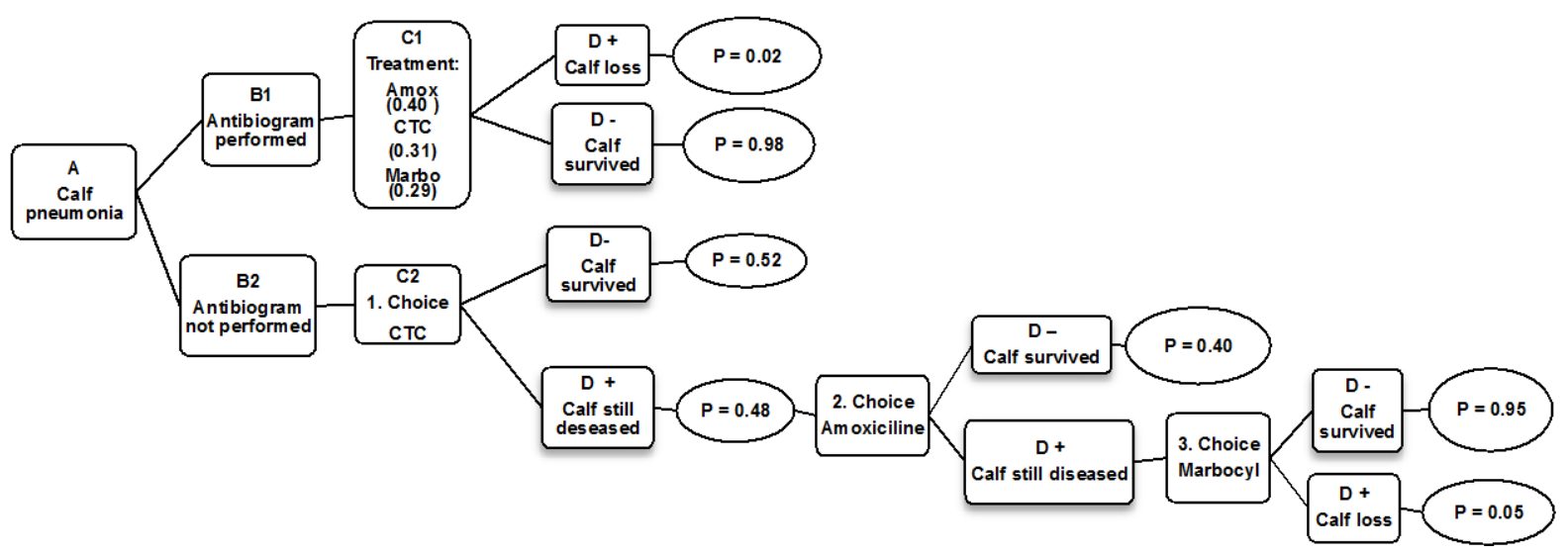

Figure 1. Decision tree. The explanation of the notations, calculations and probabilities are given in Table 1. 
Table 1. Notation, calculation and probabilities of the decision tree. Capital letters represent the costs within the decision tree. The figure following the capital letter represents the free choice "resistancy test" $=1$ or "try and error method" $=2$. D+ = diseased, $\mathrm{D}-=$ healthy. $\mathrm{P}=$ probabilitynad subscript to $\mathrm{P}=\mathrm{P}$ for a certain branch. $+=$ positive outcome, $-=$ negative outcome. Amox = Amoxicillin, CTC = Chlortetracycline, Marbo $=$ Marboxyl.

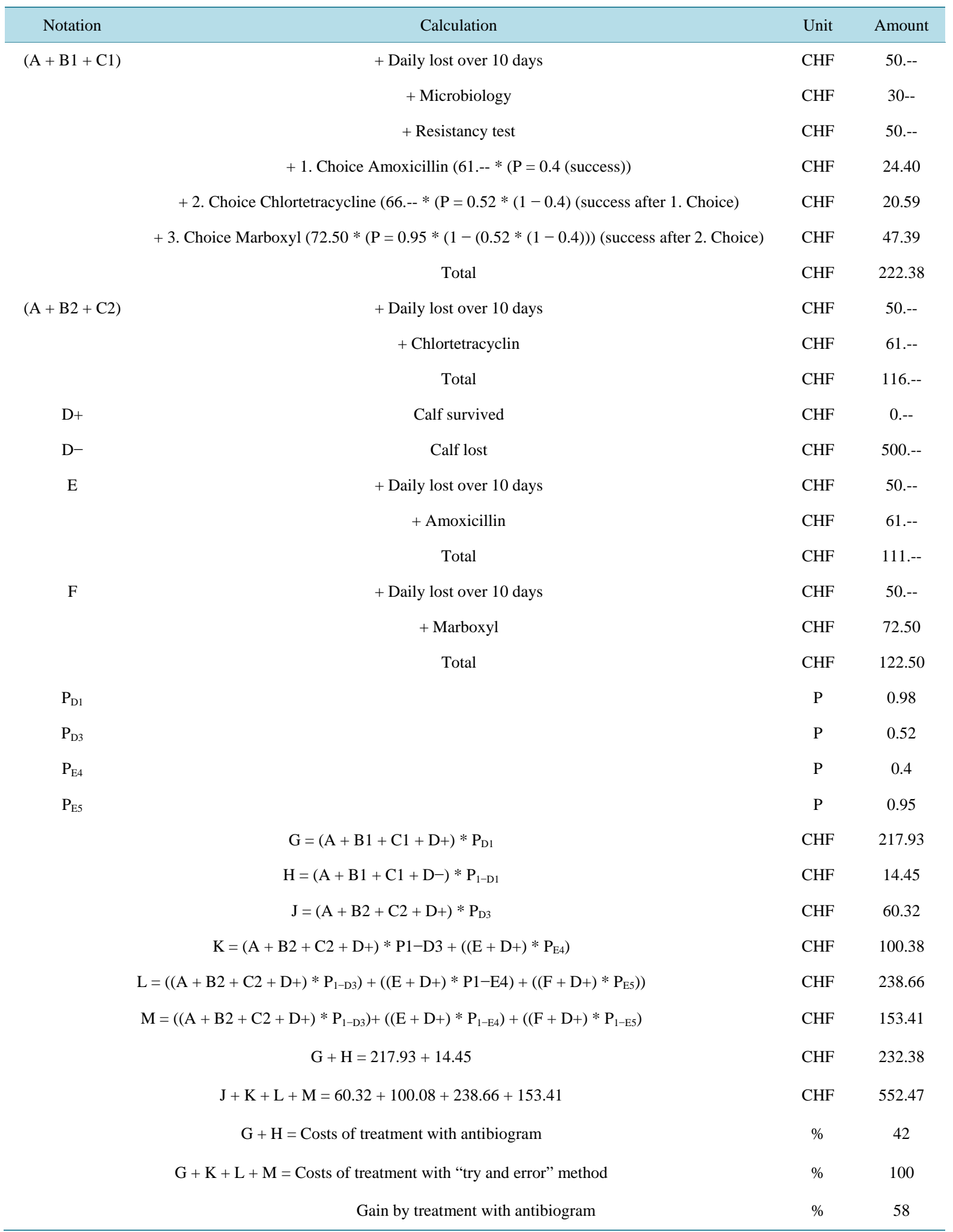


Resistance was measured on a herd level by combining at least three deep nasal swaps. Only ++ to +++ growth was considered as important. Growth of only + and mixed flora were not considered as important. The SOP to ensure a high quality sample of microbiological flora responsible for pneumonia in calves is a tracheal lavage. This SOP is time consuming, and therefore expensive, and the results give only a point estimate in herd health nasal swaps of at least three animals with the restricted interpretation. As mentioned previously, this approach is widely established in herd health medicine in Switzerland.

The overall situation of antimicrobial resistance within the Swiss farm animal population is stable [7]-[9]. The prevalence of antimicrobial resistance important for human medicine is very low in meat calf [10]. The reduction of antimicrobial drug use in animals is mandatory. Meat calves can be the reservoir for resistant bacteria [11].

Since 1999 the use of antibiotics for growth promotion is forbidden in Switzerland [10]. In the meantime the EU has similar regulations. Additionally, the use of antibiotics has to be documented in Switzerland [12].

The emergence of multi-drug resistant (MDR) bacteria is a major public health concern worldwide. Using an antimicrobial resistance test prior to the treatment of food animals, such as meat calves, can help mitigate this important issue by avoiding the selection of resistant bacteria, provided that the antibiotic drug is applied according to good clinical practice, i.e. correct dosage over sufficient time.

\section{Conclusion}

The procedure presented here would not only help to control the presence and emergence of resistance, but also limit the volume of antibiotic drugs required for effective treatment. Such a clinical procedure has to be established by international and national drug agencies. Antimicrobial resistance test has to be mandatory when antibiotics are used on a herd level or in single animal treatment longer than 3 days. Further studies on this clinical procedure have to prove its validity. The decision tree analysis presented provides strong support in favour of an antimicrobial treatment by using an antimicrobial resistance test, not only as "good veterinary practice" or ecological gain but also as a financial or economical gain.

\section{References}

[1] Hassig, M., Stadler, T. and Lutz, H. (2007) Transition from Maternal to Endogenous Antibodies in New Born Calves. Veterinary Record, 160, 234-235.

[2] Hässig, M., Wetli, U., Lutz, H. and Suter, M. (2012) Einflusskolostraler Antikörper auf die postvakzinale Immunantwortbeineonatalen Kälbern. Schweizer Archive fürTierheilkunde, 154, 141-147.

[3] Hässig, M., Eugster, S. and Lewis, F.I. (2014) Herd Level Antimicrobial Resistance in Beef Calves in Switzerland 1986 through 2011. Open Journal of Veterinary Medicine, 4, 247-254.

[4] Altman, D.G. (1994) Practical Statistics for Medical Research. Chapman \& Hall, London.

[5] Anonym (2010) ARCH-VET: Berichtüber den Vertrieb von Antibiotika in der Veterinärmedizin und das Antibiotikaresistenzmonitoringbei Nutztieren in der Schweiz. Bundesamtfür Veterinärwesen BVET, Swissmedic Schweizerisches Heilmittelinstitut. www.blv.admin.ch/dokumentation/04506/04518/index.html

[6] Filippini, M., Masiero, G. and Moschetti, K. (2006) Socioeconomic Determinants of Regional Differences in Outpatient Antibiotic Consumption: Evidence from Switzerland. Health Policy, 78, 77-92.

[7] Anonym (2012) CLINIPHARM: Baytril 10\% ad us. vet., Arzneimittelvormischung. http://www.vetpharm.uzh.ch/reloader.htm?tak/05000000/00058995.01?inhalt_c.htm

[8] Anonym (2012) Die Bundesbehörden der Schweizerischen Eidgenossenschaft: Weniger Antibiotika in der Veterinärmedizin. BVET, Swissmedic. http://www.news.admin.ch/message/index.html?lang=de\&msg-id=41281

[9] De La Torre, A., Iglesias, I., Carballo, M., Ramirez, P. and Munoz, M.J. (2011) An Approach the Vulnerability of European Union Soils to Antibiotic Contamination. Science Total Envirional, 414, 672-679.

[10] Anonym (2001) Bundesamtfür Veterinärwesen: Zoonosebericht 2001, Antibiotikaresistenz (2001) BVET Magazin. www.blv.admin.ch/dokumentation/00327/04538/.../index.html

[11] Di Labio, E., Regula, G., Steiner, A., Miserez, R., Thomann, A. and Ledergerber, U. (2007) Antimicrobial Resistance in Bacteria from Swiss Veal Calves at Slaughter. Zoonoses Public Health, 54, 344-352.

[12] Anonym (2000) Koordinationsgruppeantibiotikaresistente Mikroorganismen: Bakterielle Antibiotikaresistenz in den Bereichen Humanmedizin, Veterinärmedizin und Lebensmittel. Universität Zürich, Universität Bern, Lugano, ETH Zürich, Bundesamtfür Gesundheit. www.news.admin.ch/NSBSubscriber/message/attachments/2390.pdf 